University of South Carolina

Scholar Commons

1984

\title{
Who Volunteers for Adult Development Research? Research Findings and Practical Steps to Reach Low Volunteering Groups
}

Michael Todd

Keith E. Davis

University of South Carolina - Columbia, daviske@sc.edu

Thomas P. Cafferty

University of South Carolina - Columbia, cafferty@sc.edu

Follow this and additional works at: https://scholarcommons.sc.edu/psyc_facpub

Part of the Psychology Commons

Publication Info

Published in International Journal of Aging and Human Development, ed. Bert Hayslip Jr., Volume 18, Issue 3,1984 , pages 177-184.

http://www.baywood.com/journals/PreviewJournals.asp?ld=0091-4150

(c) 1984 by Baywood Publishing Company, Inc.

This Article is brought to you by the Psychology, Department of at Scholar Commons. It has been accepted for inclusion in Faculty Publications by an authorized administrator of Scholar Commons. For more information, please contact digres@mailbox.sc.edu. 


\title{
WHO VOLUNTEERS FOR ADULT DEVELOPMENT RESEARCH?: RESEARCH FINDINGS AND PRACTICAL STEPS TO REACH LOW VOLUNTEERING GROUPS*
}

\author{
MICHAEL TODD \\ KEITH E. DAVIS \\ THOMAS P. CAFFERTY \\ University of South Carolina
}

\begin{abstract}
The present study is an attempt to determine volunteering bias in racial, gender, and age groups in an adult development study. Samples were drawn from three different types of organizations in the Columbia, South Carolina SMSA. Volunteering rates were calculated as a function of the number eligible to participate in three age groups: 1) young adult (aged 20-25);2) middle adult (aged 40-45); and 3) old (aged 60-80). The middle group volunteered at a higher rate than the other two age groups, but this effect was restricted to the white sample. Women volunteered more readily than men, but not among the elderly. Whites volunteered more readily than blacks. In order to overcome these volunteering biases, special recruitment procedures were employed in order to obtain a sample which adequately represents the populations in question.
\end{abstract}

While the study of volunteer bias in behavioral science research has been an issue of significant concern, there are few studies comparing volunteer effects on both adult and elderly populations. This study addresses the implications of volunteer bias for adult development research, and suggests some steps that will enable the researcher to increase the volunteering rate for hard-to-get participants.

*The research reported in this article was made possible by funding from a Special Initiation Grant for Gerontological Research from the National Institute on Aging (\#5R21-Ag01571).

(C) 1984, Baywood Publishing Co., Inc. 
Most studies are of volunteer versus nonvolunteer comparisons within adult and student groups. Maslow and Sakoda, for example, in their work on "volunteer error" in the Kinsey study, noted that volunteers inflated the percentage who reported unconventional sexual behavior in sex studies [1]. Similar results were obtained by Kaats and Davis, who found that individuals voluntarily attending a study of sexual behavior were more likely to hold liberal sexual attitudes and to have more noncoital sexual experience than nonvolunteers [2]. Volunteer effects have also been found in a study of marital counseling. Kirby and Davis reported that couples who refused to volunteer for counseling had dated for a shorter time before marriage, had lower socio-economic status, less education, and fewer children than volunteering couples [3]. Joe, Jones, and Ryder found that volunteer effects may be related to the type of study [4] . Their findings indicated that very conservative people are less willing to volunteer for experiments which may appear threatening to them, such as those concerning human sexual response, than less conservative people. Rush, Phillips, and Panek, comparing paid versus unpaid volunteers, found the latter group to be more interpersonally oriented and more field dependent [5] . Remington, Taylor, and Buskirk, however, did not find evidence of volunteering effects in chronic disease studies [6].

Thus, while volunteers have generally been found to differ from nonvolunteers, only Rosenthal and Rosnow [7], and Lykken, Tellegen, and Derubeis [8] appear to have addressed the question of the likelihood of various populations to volunteer. Rosenthal and Rosnow, having surveyed the research on volunteer characteristics, note that volunteers tend to be better educated, have higher social class status, and are more intelligent (except in some less typical types of research) [7]. They also noted that females are more likely to volunteer for research in general, but not for stressful research, such as that involving electric shock, or interviews about sex behavior. In addition, they noted that there is some evidence to suggest that volunteers tend to be younger than nonvolunteers

Lykken, Tellegan and Derubeis found that studies of same-sex twins generally use samples consisting of two-thirds females and two-thirds monozygotic (MZ) twins [8]. Therefore, male and dizygotic (DZ) twins are underrepresented with respect to their populations. In order to overcome recruitment bias, Lykken, Tellegen, and Derubeis suggested that strong incentives to participate be provided to the underrepresented groups.

The nature of potential biases in rate of volunteering among the elderly is less well documented. The aim of this study is both to document volunteering biases for a type of study-one dealing with life satisfaction, social networks, and quality of life-and to provide evidence about some steps likely to reduce these biases.

\section{METHOD}

Because our research design was to approach large public and private agencies and secure management's cooperation in soliciting all eligible employees, we were able to count the number of volunteers for a study on adult development as a function of the number eligible to participate in three age groups: 1) young adult (aged 20-25);2) middle adult (aged 40-45); and 3) old groups: 1) Two of the three agencies had data on retirees, so we could (aged 60-80). Two of the three agencies had data on sorided into preretirement and postretirement groups. These data were collected as into preretirement and postretirement groups. These dat and life satisfaction [9] part of a short-term longitudinal study of social networks and life satisfaction [9]

Our target sample size was 350 , with the sample to consist of four women to three men, two whites to one black (which is the approximate population ratio in the SMSA), and 150 elderly to 100 in each of the two younger age groups. Recruitment for volunteers was conducted over a fourteen-month period from Jecruitment 1980 to the end of February 1981. On the basis of the research literature, we anticipated that women would volunteer more readily than men literature whe readily than blacks. Participants were and that whites would voluntee pools of three large organizations: a state university (nonfaculty employees), a private insurance company, and an urban school district.

Solicitation was done in two phases. In Phase I, university and corporate employees were recruited by means of stimulus material requesting

.. your participation in a study we are conducting as members of the Psychology Department at the University of South Carolina. All employees or retired employees between the ages of twenty and twenty five, forty and forty-five, and sixty or older are eligible to participate. The age ranges were approved by the granting agency. And we would like to offer you five dollars for your participation....

The study is concerned with some aspects of adult development and is funded by a grant from the National Institute of Aging. .

We are seeking people of various ages who would be willing to be interviewed for about one-and-a-half hours sometime this Spring and once again in about two years. The specific time and place for the interview will be scheduled at your convenience. For your participation in the one interview this Spring, we are offering five dollars to be paid to you.

The general purpose of this study is to shed light on the way our social relationships develop and change over life and the role they play in helping us cope with life's problems. It is also designed to examine changing goals and ambitions in life as these affect our feelings of happiness and well-being.

After Phase I was completed, we had achieved about 60 percent of our goal for for the research sample. Preliminary analysis of the volunteering data from the first two agencies confirmed that women and whites were volunteering more readily than men and blacks. We also found that the elderly sample was not volunteering as readily as we had hoped. Two general steps were taken to deal with these trends. In selecting the third and fourth businesses/agencies to approach for Phase II, we made a determined effort to get those with large male 
and black work forces. ${ }^{1}$ In this way we could reach our sample composition targets even if the rate of volunteering was lower. The second step involved both redesigning the recruiting materials and developing an active solicitation program for elderly, black, and male volunteers.

In Phase II, urban school district employees were solicited with a letter that read, in part:

The Administration of your school district has kindly agreed to assist us in making you aware of an opportunity to participate in a nationallyfunded research project on adult development. Since the publication of Passages and The Seasons of a Man's Life, there has been a growing interest in major changes in people's lives in the period from starting a career and family through the cycle to retirement and post-retirement. Our research study will be one of the first dealing with these issues to have a broad cross-section of the community involved, to have a significan number of women as well as men and to have significant participation from the black community. Already we have had 220 Columbians from all walks of life and backgrounds who have participated, and we hope that you will be willing to help us by setting aside approximately one and onehalf hours for one of our trained staff to interview you.

In other respects the solicitation was identical to that used in Phase I.

\section{RESULTS}

First we shall examine the volunteering effects in our three agency samples and then look at the efficacy of the steps taken to reduce their influence on our practical research goals.

Separate $\chi^{2}$ analysis for each of the three agencies indicated that the same trends held, so we have combined all three data sources into one table for presentation. In Table 1, it is clear that all three classification variables had significant main effects, but that the three variables also interacted with each other. Whites volunteered more readily than blacks $\left(\chi^{2}=19.62, \mathrm{df}=1, p<\right.$ $.001, \Phi=.26$ ). The middle-aged group volunteered more readily than either young adults or the elderly $\left(\chi^{2}=6.74, \mathrm{df}=2, p<.05, \Phi .14\right)$, but this effect was limited to the white sample. Consistent with Rosenthal and Rosnow's findings [7], women volunteered more readily than men, but this trend did not hold among the elderly.

Both of the agencies solicited in Phase I were able to provide us with data on the job level of each employee. Employees were classified as managerial/ supervisory vs. nonmanagerial, and in both agencies this was the most powerful

${ }^{1}$ After we had secured preliminary permission to solicit volunteers from a large sporting goods manufacturing company which had a largely male work force, the company was bought out by a nonlocal conglomerate. Permission to solicit and to interview employee was withdrawn. The newcomers did not want any psychologists talking to employees during the tense time of transition to new management.
Table 1. Volunteering Rates as a Function of the Number Eligible to Participate

\begin{tabular}{|c|c|c|c|c|c|}
\hline \multirow{2}{*}{$\begin{array}{r}\text { Race: } \\
\text { Gender: }\end{array}$} & \multicolumn{2}{|c|}{ White } & \multicolumn{2}{|c|}{ Black } & \multirow{2}{*}{$\begin{array}{l}\text { Totals by } \\
\text { Age Groups }\end{array}$} \\
\hline & Men & Women & Men & Women & \\
\hline \multicolumn{6}{|l|}{ Age Groups: } \\
\hline $20-25$ & 116 & 460 & 88 & 150 & 814 \\
\hline & $13.8 \%$ & $18.0 \%$ & $10.2 \%$ & $15.3 \%$ & $16.1 \%$ \\
\hline $40-45$ & 98 & 244 & 89 & 271 & 702 \\
\hline & $20.4 \%$ & $31.5 \%$ & $10.1 \%$ & $11.8 \%$ & $19.6 \%$ \\
\hline $60-80$ & 97 & 163 & 83 & 70 & 413 \\
\hline & $16.4 \%$ & $15.3 \%$ & $9.6 \%$ & $8.6 \%$ & $13.3 \%$ \\
\hline \multicolumn{6}{|l|}{ Totals by race and } \\
\hline \multirow[t]{2}{*}{ gender: } & 311 & 867 & 260 & 491 & \\
\hline & $16.7 \%$ & $21.3 \%$ & $10.0 \%$ & $12.4 \%$ & \\
\hline \multirow[t]{2}{*}{ Totals by race: } & White & 1178 & Black & 751 & \\
\hline & & $20.1 \%$ & & $11.6 \%$ & \\
\hline \multirow[t]{2}{*}{ Totals by gender: } & Male & 571 & Women & 1358 & \\
\hline & & $13.7 \%$ & & $18.1 \%$ & \\
\hline
\end{tabular}

Note: The first number in each category represents the number eligible to participate. The second number represents the volunteering rate for each category. The overall volunteering rate was 16.7 percent.

predictor of volunteering that we had. The $\chi^{2}$ for the combined data is 271.48 , $p<.0001$, with a $\Phi$ of .53. While Rosenthal and Rosnow indicate that volunteers tend to be from higher SES backgrounds, it appears that when volunteers are solicited with management's approval volunteering tends to be strongly related to one's position in the managerial-administrative hierarchy.

\section{Effectiveness of Interventions}

While the overall volunteering rate was 16.7 percent, the three agencies differed significantly among themselves. $\left(\chi^{2}=6.14 \mathrm{df}=2, p<.05\right)$. The Phase II agency (the urban school district) had the higher rate of volunteering (19\% vs. $15 \%$ ), but the rate of volunteering by blacks and males was not significantly higher than in Phase I.

The special recruiting efforts did allow us to complete our sample largely but not entirely as we intended. As can be seen in Table 2 (our sample table), we did not quite achieve a four women to three men ratio, but rather approximately two women to one man; nor did we get 150 elderly to 100 in the two younger 
Table 2. Sample as a Function of Age/Cohort, Gender, and Race $(N=346)$

\begin{tabular}{|c|c|c|c|c|c|c|c|c|c|}
\hline \multirow[b]{3}{*}{ Gender: } & \multicolumn{8}{|c|}{ Age/Cohort } & \multirow[b]{3}{*}{ Subtotals } \\
\hline & \multicolumn{2}{|c|}{$20-25$} & \multicolumn{2}{|c|}{$40-45$} & \multicolumn{2}{|c|}{60.65} & \multicolumn{2}{|c|}{$66-80$} & \\
\hline & $M$ & $F$ & $\bar{M}$ & $F$ & $M$ & $F$ & $M$ & $F$ & \\
\hline \multicolumn{10}{|l|}{ Race: } \\
\hline White & 25 & 47 & 14 & 51 & 19 & 22 & 11 & 25 & 214 \\
\hline Black & 12 & 23 & 13 & 28 & 11 & 7 & 14 & 22 & 130 \\
\hline Other & 1 & 0 & 1 & 0 & 0 & 0 & 0 & 0 & 2 \\
\hline \multirow{3}{*}{ Subtotals } & 38 & 70 & 28 & 79 & 30 & 29 & 25 & 47 & \\
\hline & 1 & & & & & & & 2 & \\
\hline & & & \multicolumn{7}{|c|}{131} \\
\hline
\end{tabular}

groups, but rather only 131 elderly. In general, however, the practical steps taken to increase the sample were effective.

\section{DISCUSSION}

This study is a contribution to the systematic analysis of volunteering effects for research on adult development. While the situation has changed from the 1970s, in which 70 percent to 90 percent of the published data on normal adults was based on college-attending, college-aged students [7], we still know all too little about who volunteers for research on adult development in the middle-aged and elderly populations. Our findings are consistent in many respects with Rosenthal and Rosnow's summary of this field [7], but importan modifications to their conclusions are suggested. While young and middle-aged women (both black and white) volunteered more readily than men in the same age categories, among the sixty to eighty year olds this differential disappeared. While we do not have systematic data to explain this change, unsystematic interviews with elderly women suggested that both fear of strangers and uncertainty about how their lives would be evaluated by psychological researchers deterred many from taking part.

Our data also suggest, contrary to a conclusion warranting some confidence, that "volunteers tend to be younger [7, p. 196]" and that the middle-aged volunteer more readily than either the young adult or elderly populations. This effect was, however, restricted to the white sample. An interpretation of this effect is that volunteering in our study-which solicited participation within an agency or company with the approval of management-is an aspect of one's general participation in the community-approved activities. The middle-aged are typically more active in this area.
While whites volunteered more readily than blacks, the level of black volunteering was high enough to enable us to complete the sample. Explicit mention of the fact that our research team had black members, and the use of mention solicitors of volunteers through informal social networks, clearly helped us to obtain a large number of black adults, but these steps did not change the rate of volunteering.

Clearly, however, the most powerful determinant of volunteering in this study was one's position in the agency/company hierarchy. The $\Phi$ value of .53 was very substantial. The managerial/supervisory employees in both the university and the insurance company offered to participate at a much higher rate than clerical/custodial employees.

These data bear a striking resemblance to the description of the Baltimore Longitudinal sample [10]. In that study, U.S. government employees at all job levels within the agencies were offered a free physical examination and time off from work to participate in the research study; yet the sample consisted of 88 percent college graduates and 63 percent with postbaccalaureate education. These findings suggest that research on adult development will have to continue to take active steps to solicit the less well placed in society if their findings are to be truly representative of the population.

The practical steps to improve our volunteering rates did not have a demonstrable effect in increasing the rate of volunteering, but the attention that we paid to several of Rosenthal and Rosnow's suggestions for reducing volunteering bias clearly helped us to obtain the sample that we got.

\section{REFERENCES}

1. A. H. Maslow and J. M. Sakoda, Volunteer-error in the Kinsey Study, Journal of the Abnormal and Social Psychology, 47:2, pp. 259-267, 1952.

2. G. R. Kaats and K. E Davis, Effects of Volunteer Biases in Studies of Sexua Behavior and Attitudes, The Journal of Sex Research, 7:11, pp. 26-34, 1971 .

3. M. W. Kirby and K. E. Davis, Who Volunteers for Research on Marital Counseling?, Journal of Marriage and the Family, 34:3, pp. 469-473, 1972.

4. V. C. Joe, R. N. Jones, and S. Ryder, Conservatism, Openness to Experience, and Sample Bias, Journal of Personality Assessment, 41:5, pp. 527-531, 1977.

5. M. Rush, J. S. Phillips, and P. E. Panek, Subject Recuritment Bias: The Paid Volunteer Subject, Perceptual and Motor Skills, 47:2, pp. 443-449, 1978.

6. R. D. Remington, H. L. Taylor, and E. R. Buskirk, A Method for Assessin Volunteer Bias and its Application to a Cardiovascular Disease Prevention Programme Involving Physical Activity, Journal of Epidemiology and Community Health, 32:4, pp. 250-255, 1978.

7. R. Rosenthal and R. L. Rosnow, The Volunteer Subject, John Wiley and Sons, New York, 1975

8. D. T. Lykken, A. Tellegen, and R. Derubeis, Volunteer Bias in Twin Research: The Rule of Two-Thirds, Social Biology, 25:1, pp. 1-9. 1978. 
9. K. E. Davis and T. P. Cafferty, Research Initiation Grant for Gerontological Research, National Institute of Aging (5R21-Ag01571), July 1, 1979June 30,1982. (Available from the authors).

10. J. L. Stone and A. H. Norris, Activities and Attitudes of Participants in the Baltimore Longitudinal Study, Journal of Gerontology, 21:5, pp. 575-580, 1966.

Direct reprint requests to:

Keith E. Davis

Department of Psychology

University of South Carolina

Columbia, SC 28208 